\title{
Structure and Properties of Electrochemically Synthesized Silver Nanoparticles in Aqueous Solution by High-Resolution Techniques
}

\author{
Carla Gasbarri 1 ${ }^{(D}$, Maurizio Ronci ${ }^{2}\left(\mathbb{D}\right.$, Antonio Aceto ${ }^{2}$, Roshan Vasani ${ }^{3}$, Gianluca Iezzi ${ }^{4}$, Tullio Florio ${ }^{5,6} \mathbb{D}$, \\ Federica Barbieri ${ }^{5}$ (D), Guido Angelini ${ }^{1}$ (D) and Luca Scotti ${ }^{2, *(D)}$
}

1 Department of Pharmacy, University “G. d'Annunzio" of Chieti-Pescara, Via dei Vestini, 66100 Chieti, Italy; carla.gasbarri@unich.it (C.G.); guido.angelini@unich.it (G.A.)

2 Department of Medical, Oral and Biotechnological Sciences, University "G. d'Annunzio" of Chieti-Pescara, Via dei Vestini, 66100 Chieti, Italy; maurizio.ronci@unich.it (M.R.); antonio.aceto@unich.it (A.A.)

3 Monash Institute of Pharmaceutical Sciences, Monash, VIC 3800, Australia; roshan.vasani@monash.edu

4 Dipartimento di Ingegneria and Geologia, Università G. d'Annunzio, Via dei Vestini 30, 66013 Chieti, Italy; gianluca.iezzi@unich.it

5 Department of Internal Medicine and Center of Excellence for Biomedical Research (CEBR), University of Genova, 16132 Genova, Italy; tullio.florio@unige.it (T.F.); federica.barbieri@unige.it (F.B.)

6 IRCCS Ospedale Policlinico San Martino, 16132 Genova, Italy

* Correspondence: luca.scotti@unich.it or 1.scotti@unich.it; Tel.: +39-0871-3554721

\section{check for}

updates

Citation: Gasbarri, C.; Ronci, M.; Aceto, A.; Vasani, R.; Iezzi, G.; Florio, T.; Barbieri, F.; Angelini, G.; Scotti, L. Structure and Properties of

Electrochemically Synthesized Silver Nanoparticles in Aqueous Solution by High-Resolution Techniques. Molecules 2021, 26, 5155. https:// doi.org/10.3390/molecules26175155

Academic Editor: M. Concepción Gimeno

Received: 14 July 2021

Accepted: 23 August 2021

Published: 25 August 2021

Publisher's Note: MDPI stays neutral with regard to jurisdictional claims in published maps and institutional affiliations.

Copyright: (C) 2021 by the authors Licensee MDPI, Basel, Switzerland. This article is an open access article distributed under the terms and conditions of the Creative Commons Attribution (CC BY) license (https:/ / creativecommons.org/licenses/by/ $4.0 /)$.

\begin{abstract}
The aim of this work was to deeply investigate the structure and properties of electrochemically synthesized silver nanoparticles (AgNPs) through high-resolution techniques such as transmission electron microscopy (TEM), scanning electron microscopy (SEM), Zeta Potential measurements, and matrix-assisted laser desorption/ionization time of flight mass spectrometry (MALDI-TOF-MS). Strong brightness, tendency to generate nanoclusters containing an odd number of atoms, and absence of the free silver ions in solution were observed. The research also highlighted that the chemical and physical properties of the AgNPs seemed to be related to their peculiar oxidative state as suggested by X-ray photoelectron spectroscopy (XPS) and X-ray powder diffraction (XRPD) analyses. Finally, the MTT assay tested the low cytotoxicity of the investigated AgNPs.
\end{abstract}

Keywords: silver nanoparticles; X-ray analysis; electron microscopy; oxidative state; cytotoxicity

\section{Introduction}

Over the last decade, the range of applications of silver nanoparticles (AgNPs) has been continuously developing, given their unusual properties and features. AgNPs have already been successfully employed in many different areas including catalysts, electronic, magnetic, and optical nanomaterials, antibacterial agents, and thermally conductive nanofluids up to their inclusion into textile and cosmetics products [1-9]. Recently, strong antibiotic activity of AgNPs against both planktonic and biofilm phenotypes of Pseudomonas aeruginosa and other cystic fibrosis-associated bacterial pathogens was also observed [10]. Moreover, the role of these nanoparticles as interactive but not reactive media for azobenzene isomerization has been demonstrated by kinetic, spectroscopic, and Zeta Potential measurements [11].

In general, size, shape, morphology, and physical and chemical properties of metal nanoparticles are strongly affected by the experimental conditions in which their synthesis occurs [12,13].

Different methods have been proposed to produce silver nanoparticles, including laser ablation and the photochemical approach [12-15]. However, despite its potential versatility both in organic solvents and aqueous solutions [16,17], electrochemical synthesis remains limited to few applications $[18,19]$. This method is based on different steps: 
anode oxidation-cathode reduction reactions, hydrogen and oxygen formation from water electrolysis, and side reactions [20]. Only a small amount of hydrogen peroxide is usually needed to reduce the silver oxide in the solution, while stabilizers or coating agents, such as tetrabutyl ammonium salts or poly-(N-vinylpyrrolidone), are added [21,22] in order to control the size and the release of the silver into the surrounding media [23,24].

It is acknowledged that a single surface plasmon resonance band in the UV-Vis region around $400 \mathrm{~nm}$ is related to spherical nanoparticles [25], even if some factors can affect the extinction coefficients [26,27]. However, the aggregation of silver nanoparticles may also easily occur in this case, and different techniques can be employed to observe the aggregation phenomena in colloidal systems over time [28-35].

Based on a novel and fast fabrication method using a device built in-house, uncoated and negatively charged AgNPs have been electrochemically synthesized in an aqueous solution and without stabilizer. The obtained AgNPs were spherical and monodispersed in a solution, which showed high stability according to UV-vis spectroscopy analysis, transmission electron microscopy and field emission scanning electron microscopy images, dynamic laser light scattering, and zeta potential measurements [36]. Another application for AgNPs in the photocatalysts field-absorbing light beyond the UV-visible region and catalyzing reactions using the collected upconverted (NIR to UV-visible) photon energy - has received actual attention [37,38]. Moreover, kinetic, spectroscopic, and zeta potential demonstrate the role of these nanoparticles as interactive but not reactive media for azobenzene isomerization.

The aim of this work was to explore the surface and core of the investigated nanoparticles by using high-resolution techniques such as scanning electron microscopy (SEM), transmission electron microscopy (TEM), X-ray photoelectron spectroscopy (XPS), X-ray powder diffraction analysis (XRPD), Zeta Potential measurements, and matrix-assisted laser desorption/ionization time of flight mass spectrometry (MALDI-TOF).

\section{Materials and Methods}

\subsection{AgNPs Preparation}

The modified synthesis of AgNPs in aqueous solution is based on the electrochemical dissolution of pure $99.9 \%$ silver electrodes in pure water and applying a low electrical current, as previously described [36]. The power supply and a home-made electronic board were assembled for the synthesis. Voltage, current, reaction time, and total electrical power were optimized and monitored during all the electrochemical processes (Patent Application EP 18181873).

\subsection{Zeta Potential and Oxidation Reduction Potential (ORP) Measurements}

The Zeta Potential analysis was carried out at $25{ }^{\circ} \mathrm{C}$ using a 90PLUS BI-MAS (Brookhaven, MS, USA) equipped with digital correlator at a scattering angle of $15^{\circ}$, with a $35 \mathrm{~mW} \mathrm{He}-\mathrm{Ne}$ laser at the wavelength of $660 \mathrm{~nm}$. An electrode ORP $(\bmod 98201$, Hanna Instruments) and a dithiothreitol solution (DTT, $20 \mathrm{ug} / \mathrm{mL}$ ) were employed as standard for ORP analysis.

\subsection{TEM and SEM Analysis}

TEM images were taken after the evaporation of a drop of AgNPs diluted solution on 300 mesh formvar coated nickel grids at $75 \mathrm{kV}$ by using a ZEISS 109 microscope equipped with a Gatan-Orius SC200W-Model 830.10W TEM CCD Camera. SEM images were obtained from the powder after the complete evaporation of the AgNPs solution at $40{ }^{\circ} \mathrm{C}$ under a nitrogen flow by using a Sigma 300 Zeiss microscope equipped with an elemental microanalysis apparatus Quantax-200 Bruker.

\subsection{XPS and XRPD Analysis}

XPS analysis was performed using an AXIS Nova spectrometer (Kratos Analytical Inc., Manchester, UK) with a monochromatic $\mathrm{Al} \mathrm{K} \alpha$ source at a power of $180 \mathrm{~W}(15 \mathrm{kV} \times 12 \mathrm{~mA})$ 
and a hemispherical analyzer operating in the fixed analyzer transmission mode. XRPD pattern was collected from 4 to $90^{\circ}$ of $2 \theta$, with a step scan of $0.02^{\circ}$ and $8 \mathrm{~s}$ per step with a Rigaku Ultima IV diffractometer. Experimental data were obtained with two different sample states: solid and in solution. The solid phase was obtained by removing the solvent under nitrogen gas. Here only the results obtained with the solid phase sample are reported.

\subsection{MALDI-TOF Measurements}

The samples were prepared by adding $0.5 \mu \mathrm{L}$ of $0.1 \%$ trifluoroacetic acid to $1 \mu \mathrm{L}$ of $20 \mathrm{ppm}$ AgNPs aqueous solution deposited on the MALDI target. The analysis was performed after drying on an Autoflex Speed TOF/TOF mass spectrometer (Bruker-Daltonics $\mathrm{GmbH}$, Bremen, Germany) equipped with a Smart Beam II $1 \mathrm{kHz}$ laser, in Reflectron Positive (RP) mode, in the range of 20-1.300 Da. The instrument was controlled through Flexcontrol 3.4.135.0 software. The voltages were set as follows: $19.00 \mathrm{kV}$ and $16.70 \mathrm{kV}$ for ion source 1 and 2, respectively, $8.55 \mathrm{kV}$ for the lens, and $21.00 \mathrm{kVand} 9.60 \mathrm{kV}$ for reflector 1 and 2, respectively. Pulsed ion extraction time was set to $130 \mathrm{~ns}$. Laser fluence was kept very low to avoid unwanted fragmentation of sample clusters and adducts. The power attenuator was adjusted before the acquisition to maximize resolution, and a laser frequency of $100 \mathrm{~Hz}$ was used. For each sample spot, 5000-15,000 total shots were summed.

\subsection{Cytotoxicity Assay}

Cells (2.500 cells/well) were seeded in 96-well plates and treated with AgNPs or vehicle (PBS) in dose-response experiments after $24 \mathrm{~h}$. Cell viability was assessed after $24-48 \mathrm{~h}$ of treatment using the MTT assay, which evaluates the mitochondrial function as an index of cell viability by measuring the reduction of 3-(4,5-dimethylthiazol-2-yl)-2,5diphenyltetrazolium bromide (or MTT assay, Sigma-Aldrich, Milano, Italy) as previously reported [39]. Moreover, the $\mathrm{IC}_{50}$ values were calculated using nonlinear regression curve fit analysis with Graph Pad Prism 6.00 (GraphPad Software, San Diego, CA, USA). Data were expressed as the mean \pm standard deviation. Cell culture: HEK-293 (human embryonic kidney) cell line was maintained in Dulbecco's Modified Eagle Medium (DMEM, EuroClone, Lombardy, Italy) containing fetal bovine serum (FBS, Vicenza, Italy) to a final concentration of 10\%, 2 mM L-Glutamine (EuroClone, Lombardy, Italy), and 1\% penicillinstreptomycin (EuroClone, Lombardy, Italy).

\section{Results and Discussion}

Generally, a high absolute zeta potential value suggests that nanoparticles tend to repulse each other, avoiding any aggregation process [40,41]. The investigated AgNPs showed good stability in an aqueous solution according to the Zeta Potential values in the range $-40 /-70 \mathrm{mV}$. Statistical analysis for particle size and distribution performed by TEM on different samples highlighted a high frequency of about $3 \mathrm{~nm}$ nanoparticles, as shown in Figure 1.

It is well-known that SEM images provide information about structure, surface, and composition of nanomateria ls and nanoparticles. Examples of SEM images obtained for the AgNPs are reported in Figure 2. 


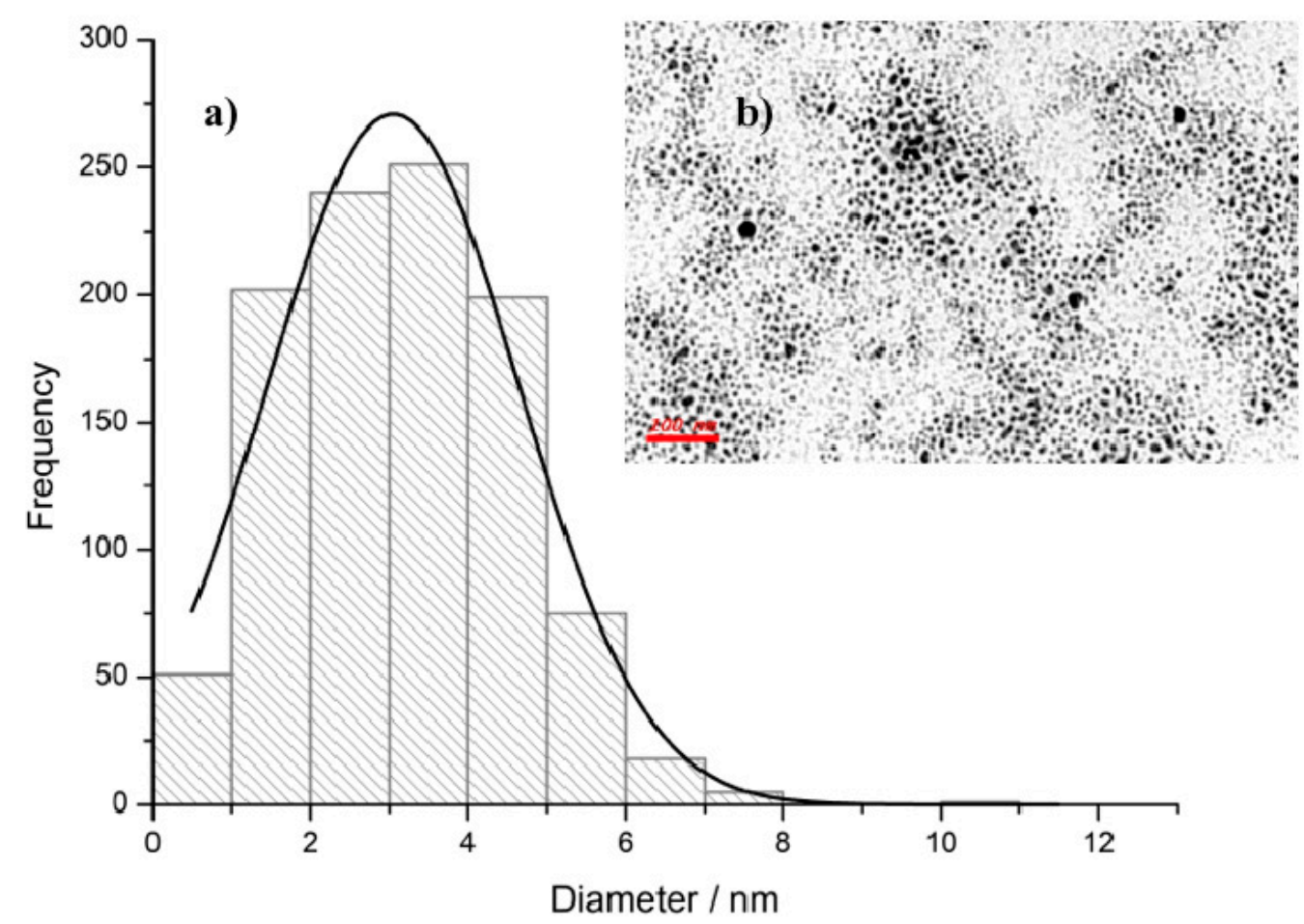

Figure 1. Panel (a): particle size distribution histogram indicating high frequency of nanoparticles in the 1-5 nm range and lack of nanoparticles larger than $8 \mathrm{~nm}$. In panel (b), a TEM micrograph of the investigated AgNPs is shown (scale bar: $100 \mathrm{~nm}$ ). The statistical distribution of nanoparticles was obtained by the elaboration of TEM images with the ImageJ program and calculated with StatPlus-2 or Origin software.
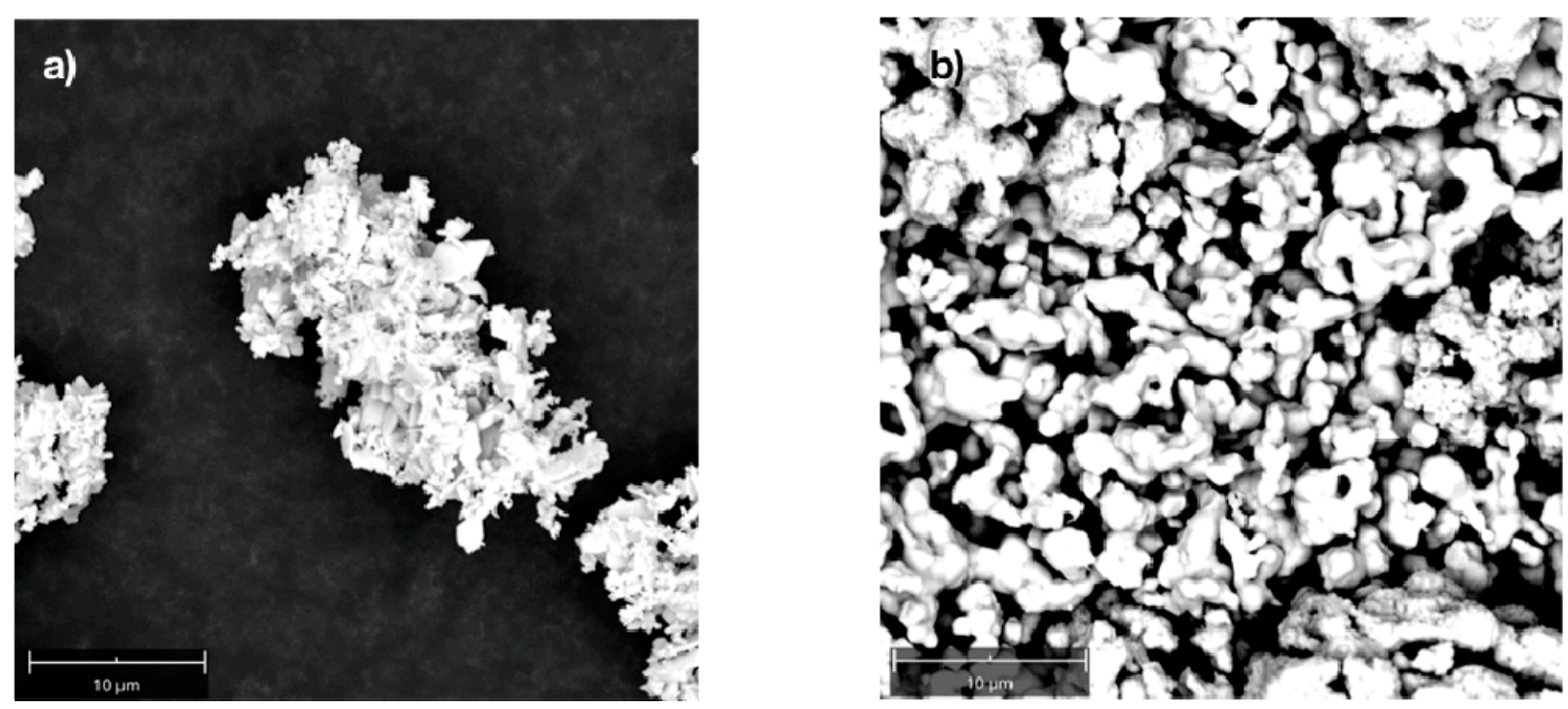

Figure 2. Example of an SEM image of the investigated AgNPs in a solid sample. Evidence of a typical charge effect of nonconductive samples (specimen) that were not treated with a "coated technique". (a) The figure was obtained with the drop technique on a metal sample holder (specimen) covered with charcoal. (b) The figure represents the magnification useful for the elementary analysis.

Silver nanoparticles have a nonspherical shape and exhibit a strong "charging-lake". Generally, charging is related to the lack of conductivity for a specimen in the so-called charging effect [42] due to the accumulation of static electric charge onto the particle sur- 
face. The results indicate that the AgNPs were nonconductive and could be considered as an insulating material. Moreover, ORP analysis revealed a value of $+400 \mathrm{mV}$ associated with silver nanoclusters in comparison to $-90 \mathrm{mV}$ obtained from the DTT standard solution, suggesting oxidative rather than reductive properties of the investigated AgNPs. Furthermore, the absence of free silver ions was demonstrated by ISE analysis [43].

The chemical state of the silver was determined by the position of the peaks associated with the binding energy of the emitted photoelectrons in the XPS spectrum. In particular, the bulk value of silver corresponds to $368.1 \mathrm{eV}$, and the core level of the binding energy shifts directly provide the metal electronic properties [44]. One of the XPS spectra obtained for the AgNPs is reported in Figure 3 as an example.

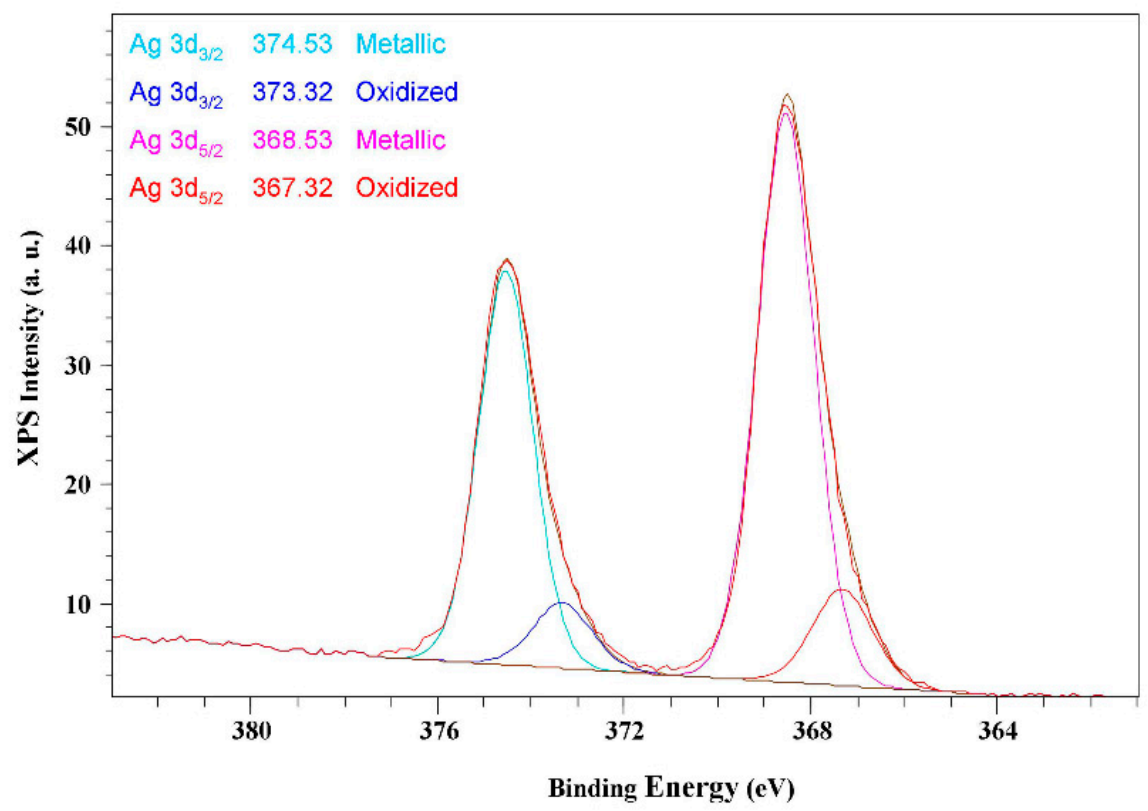

Figure 3. X-ray photoelectron spectrum of AgNPs. The binding energies are referred to as $\mathrm{Ag} 3 \mathrm{~d}_{3 / 2}$ and $\mathrm{Ag} 3 \mathrm{~d}_{5 / 2}$ in metallic and oxidized states.

The peaks at 374.53 and $373.32 \mathrm{eV}$ are associated with metallic and oxidized $\mathrm{Ag} 3 \mathrm{~d}_{3 / 2}$, respectively, while the peaks at about 368.53 and $367.32 \mathrm{eV}$ are associated with oxidized and metallic $\mathrm{Ag} 3 \mathrm{~d}_{5 / 2}$ [45]. The binding energy of metallic silver is higher than the binding energy observed in oxidized silver, therefore, the former represents the dominant state for the investigated AgNPs [46]. Moreover, the presence of $\mathrm{Ag}^{\mathrm{III}}$ was pointed out by the shift of the values toward higher binding energies, in agreement with previous studies [47,48].

$X$-ray powder diffraction analysis was performed to evaluate the oxidative state of the AgNPs. The XRPD pattern can be observed in Figure 4. The pattern peaks at $2 \theta$ values of $38.10,44.28,64.42,77.40$, and 81.50 can be attributed to the reflection of (111), (200), (220), (311), and (222) planes of the face-centered cubic silver, respectively [49,50].

The diffraction profiles of as-prepared AgNPs were broadened compared to those of bulk silver, revealing the formation of silver nanoparticles [51].

The other labeled diffraction peaks may be attributed to the $\mathrm{Ag}_{3} \mathrm{O}_{4}$ and $\mathrm{AgO}$ crystalline phases on the surface of the AgNPs [49,52]. 


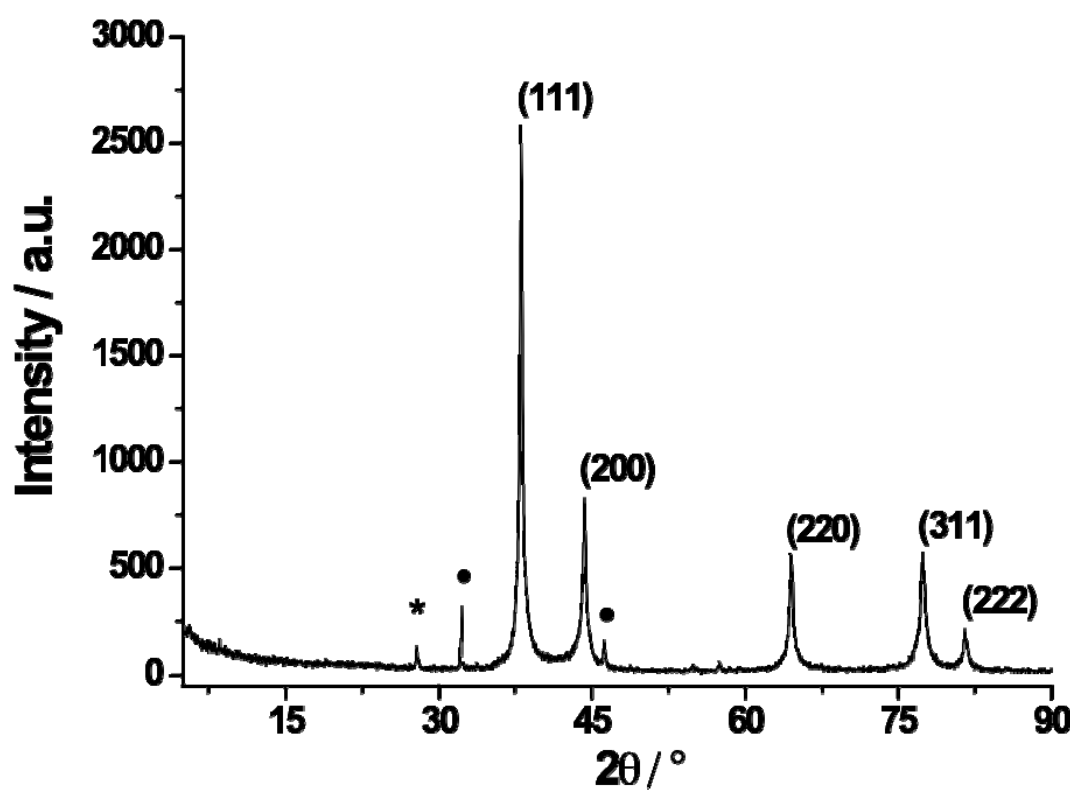

Figure 4. The XRPD pattern for the investigated AgNPs of Ag (0). The peaks marked with * and • are due to $\mathrm{Ag}_{3} \mathrm{O}_{4}$ and $\mathrm{AgO}$, respectively.

Silver nanoclusters can be also detected by MALDI-TOF mass spectroscopy analysis. Interestingly, our results showed aggregates in the low mass region that were mainly composed of an odd number of atoms (Table 1).

Table 1. Detectable (+) and not detectable (-) Ag species by MALDI-TOF mass spectrometry.

\begin{tabular}{ccccccccccccccc}
\hline $\begin{array}{c}\text { Ag Species } \\
\text { Detection }\end{array}$ & $\mathrm{Ag}$ & $\mathrm{Ag}_{2}$ & $\mathrm{Ag}_{3}$ & $\mathrm{Ag}_{4}$ & $\mathrm{Ag}_{5}$ & $\mathrm{Ag}_{6}$ & $\mathrm{Ag}_{7}$ & $\mathrm{Ag}_{8}$ & $\mathrm{Ag}_{9}$ & $\mathbf{A g}_{10}$ & $\mathbf{A g}_{11}$ & $\mathbf{A g}_{12}$ \\
\hline $\begin{array}{c}\text { Maldi-TOF MS } \\
\text { Analysis }\end{array}$ & + & + & + & - & + & - & + & - & + & - & + & - \\
\hline
\end{tabular}

Finally, the cytotoxicity of the investigated AgNPs was tested by an MTT assay on HEK-293 (human embryonic kidney). The dose-dependent curve, shown in Figure 5, demonstrated lower toxicity of AgNPs in comparison to that of $\mathrm{AgNO}_{3}$.

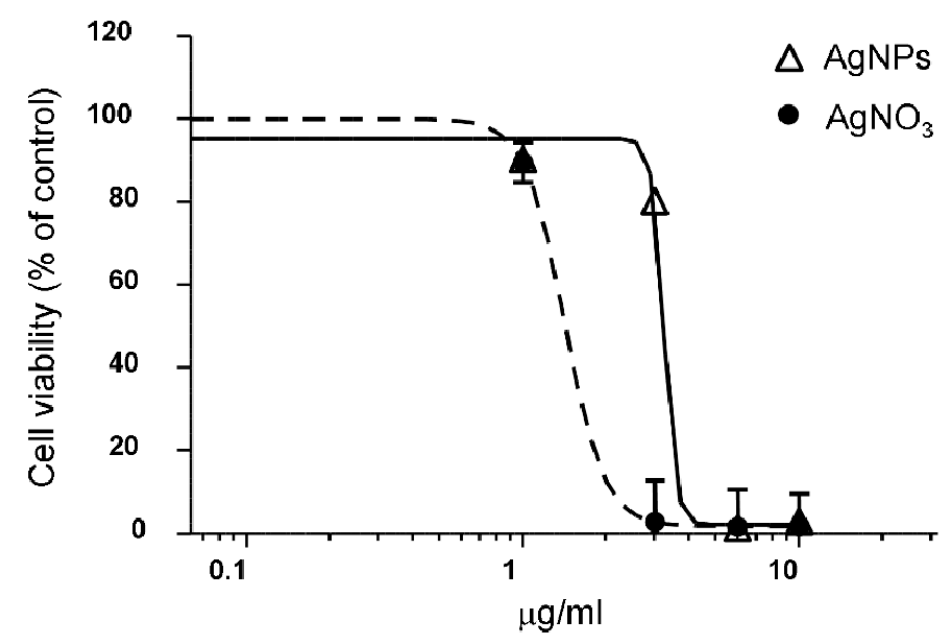

Figure 5. Dose-response curves of the effects of $\mathrm{AgNPs}$ and $\mathrm{AgNO}_{3}$ on $\mathrm{HEK}-293$ viability, evaluated by an MTT assay after $48 \mathrm{~h}$ of treatment. Data represent the mean \pm SEM of independent experiments, performed in quadruplicate. 


\section{Conclusions}

AgNPs synthesized electrochemically without adding any stabilizers or coating agents are negatively charged and monodisperse in an aqueous solution. A large population of about $3 \mathrm{~nm}$ in size and strong brightness was observed. Metallic rather than oxidized silver was the dominant state for the investigated AgNPs as suggested by an X-ray photoelectron spectrum, while the presence of oxides and the tendency to form nanoclusters was demonstrated by XPRD analysis and MALDI-TOF measurements (see Supplementary Materials). Finally, the cytotoxic effect observed by the MTT assay confirmed that the investigated AgNPs could improve the use of nanoparticles in aqueous media for a wide range of applications, both in chemical and biological fields.

Supplementary Materials: The following are available online. MALDI-TOF spectra and LeBail refined cell parameters for XRPD analysis are available as supplementary data. Figure S1: XRPD pattern, Figure S2: Geometric correlation of SUNc, Table S1: Refined LeBail cell parameters, Table S2: XRPD peak Search Report, Table S3: MALDI mono isotopic masses used for calibration.

Author Contributions: Conceptualization, investigation, supervision, L.S. data curation, writing-review and editing, G.A. and C.G., investigation, F.B., M.R., T.F., G.I., R.V. funding acquisition and Conceptualization A.A. All authors have read and agreed to the published version of the manuscript.

Funding: This work was supported by Italian Ministry of Education MIUR (60\% Grant 2018) and University "G. d'Annunzio" of Chieti-Pescara.

Institutional Review Board Statement: Not applicable.

Informed Consent Statement: Informed consent was obtained from all subjects.

Data Availability Statement: https://materialsproject.org/materials/mp-1605/ (accessed on 14 July 2021).

Conflicts of Interest: The authors declare no competing financial interest.

Sample Availability: Samples of the compounds are available only from the corresponding author.

\section{References}

1. Nowack, B.; Krug, H.F.; Height, M. 120 years of nanosilver history: Implications for policy makers. Environ. Sci. Technol. 2011, 45, 1177-1183. [CrossRef]

2. Ghosh, K.; Maiti, S.N. Mechanical properties of silver-powder-filled polypropylene composites. J. Appl. Polym. Sci. 1996, 60, 323-331. [CrossRef]

3. Krutyakov, Y.A.; Kudrinskiy, A.A.; Olenin, A.Y.; Lisichkin, G.V. Synthesis and properties of silver nanoparticles: Advances and prospects. Russ. Chem. Rev. 2008, 77, 233-257. [CrossRef]

4. Kelly, K.L.; Coronado, E.; Zhao, L.L.; Schatz, G.C. The optical properties of metal nanoparticles: The influence of size, shape, and dielectric environment. J. Phys. Chem. B 2003, 107, 668-677. [CrossRef]

5. Khan, A.U.; Wei, Y.; Ahmad, A.; Khan, Z.U.H.; Tahir, K.; Khan, S.U.; Muhammad, N.; Khan, F.U.; Yuan, Q. Enzymatic browning reduction in white cabbage, potent antibacterial and antioxidant activities of biogenic silver nanoparticles. J. Mol. Liq. 2016, 215, 39-46. [CrossRef]

6. Chernousova, S.; Epple, M. Silver as antibacterial agent: Ion, nanoparticle and metal. Angew. Chem. 2013, 52, 1636-1653. [CrossRef]

7. Emam, H.E.; Ahamed, H.B. Polysaccharides templetes for assembly of nanosilver. Carbohydr. Polym. 2016, 135, 300-307. [CrossRef] [PubMed]

8. Lee, P.C.; Meisel, D. Adsorption and surface-enhanced Raman of dyes on silver and gold sols. J. Phys. Chem. 1982, 86, 3391-3395. [CrossRef]

9. Ju, J.; Liu, W.; Perlaki, C.; Chen, K.; Feng, C.; Liu, Q. Sustained and Cost Effective Silver Substrate for Surface Enhanced Raman Spectroscopy Based Biosensing. Sci. Rep. 2017, 7, 6917. [CrossRef]

10. Pompilio, A.; Geminiani, C.; Bosco, D.; Rana, R.; Aceto, A.; Bucciarelli, T.; Scotti, L.; di Bonaventura, G. Electrochemically synthesized silver nanoparticles are active against planktonic and biofilm cells of Pseudomonas aeruginosa and other cystic fibrosis-associated bacterial pathogens. Front. Microbiol. 2018, 9, 1349. [CrossRef] [PubMed]

11. Angelini, G.; Scotti, L.; Aceto, A.; Gasbarri, C. Silver Nanoparticles as interactive media for the azobenzenes isomerization in aqueous solution: From linear to stretched kinetics. J. Mol. Liq. 2019, 284, 592-598. [CrossRef] 
12. Scott, R.W.J.; Wilson, O.M.; Crooks, R.M. Synthesis, characterization, and applications of dendrimer-encapsulated nanoparticles. J. Phys. Chem. B 2005, 109, 692-704. [CrossRef]

13. Xia, Y.; Tang, Z. Monodisperse inorganic supraparticles: Formation mechanism, properties and applications. Chem. Comm. 2012, 48, 6320-6336. [CrossRef] [PubMed]

14. Panacek, A.; Kvitek, L.; Prucek, R.; Kolar, M.; Vecerova, R.; Pizurova, N.; Sharma, V.K.; Nevecna, T.J.; Zboril, R. Silver colloid nanoparticles: Synthesis, characterization, and their antibacterial activity. J. Phys. Chem. B 2006, 110, 16248-16253. [CrossRef] [PubMed]

15. Bonnemann, H.; Richards, R.M. Nanoscopic metal particles synthetic methods and potential applications. Eur. J. Inorg. Chem. 2001, 10, 2455-2480. [CrossRef]

16. Lee, I.; Han, S.W.; Kim, K. Simultaneous preparation of SERS-active metal colloids and plates by laser ablation. J. Raman Spectrosc. 2001, 32, 947-952. [CrossRef]

17. Long, D.W.; Wu, G.Z.; Chen, S.M. Preparation of oligochitosan stabilized silver nanoparticles by gamma irradiation. Radiat. Phys.Chem. 2007, 76, 1126-1131. [CrossRef]

18. Titova, V.N.; Kazakov, V.A.; Petrova, N.V.; Białłozor, S. The influence of the solvent on the kinetics of silver electrodeposition. J. Electroanal. Chem. 1995, 381, 227-230. [CrossRef]

19. Zaky, A.M.; Assaf, F.H.; el Rehim, S.S.A.; Mohamed, B.M. Electrochemical behaviour of silver in borate buffer solutions. Appl. Surf. Sci. 2004, 221, 349-357. [CrossRef]

20. Rodrigues-Sanchez, L.; Blanko, M.L.; Lopez-Quintela, M.A. Electrochemical synthesis of silver nanoparticles. J. Phys. Chem. 2000, 104, 9683-9688. [CrossRef]

21. Gracheva, E.; Kreizberg, G.N.; Golikov, I.V. Electrochemical synthesis of silver nanoparticles. FEN-Nauka 2011, 1, 7-9.

22. Shmigel, A.V.; Tikhonov, P.A.; Arsent'ev, M.Y.; Pugachev, K.E. Electrochemical fabrication and studies of metal silver nanoparticles. Glass Phys. Chem. 2015, 41, 329-333. [CrossRef]

23. Khaydarov, R.A.; Khaydarov, R.R.; Gapurova, O.; Estrin, Y.; Scheper, T. Electrochemical method for the synthesis of silver nanoparticles. J. Nanopart. Res. 2009, 11, 1193-1200. [CrossRef]

24. Yin, B.S.; Ma, H.Y.; Wang, S.Y.; Chen, S.H. Electrochemical synthesis of silver nanoparticles under protection of poly(Nvinylpyrrolidone). J. Phys. Chem. B 2003, 107, 8898-8904. [CrossRef]

25. He, B.; Tan, J.J.; Liew, K.Y.; Liu, H. Synthesis of size controlled Ag nanoparticles. J. Mol. Catal. A Chem. 2004, 221, 121-126. [CrossRef]

26. Cáceres-Vélez, P.R.; Fascineli, M.L.; Sousa, M.H.; Grisolia, C.K.; Yate, L.; de Souza, P.E.N.; Estrela-Lopis, I.; Moya, S.; Azevedo, R.B. Humic acid attenuation of silver nanoparticle toxicity by ion complexation and the formation of a $\mathrm{Ag}^{3+}$ coating. J. Hazard. Mat. 2018, 353, 173-181. [CrossRef] [PubMed]

27. Kolwas, K.; Derkachova, A.; Shopa, M. Size characteristics of surface plasmons and their manifestation in scattering properties of metal particles. J. Quant. Spectrosc. Radiat. Transf. 2009, 110, 1490-1501. [CrossRef]

28. Gasbarri, C.; Angelini, G. Polarizability over dipolarity for the spectroscopic behavior of azobenzenes in room-temperature ionic liquids and organic solvents. J. Mol. Liq. 2017, 229, 185-188. [CrossRef]

29. Angelini, G.; Gasbarri, C. Solvent scales comparison by using $\alpha$-nitrocyclohexanone as probe in ionic liquids, organic solvents and $\mathrm{CH}_{3} \mathrm{CN} / \mathrm{CHCl}_{3}$ mixtures. Tetrahedron 2017, 73, 3036-3039. [CrossRef]

30. Gasbarri, C.; Angelini, G. Spectroscopic investigation of fluorinated phenols as pH-sensitive probes in mixed liposomal systems. RSC Adv. 2014, 4, 17840-17845. [CrossRef]

31. Angelini, G.; Pisani, M.; Mobbili, G.; Marini, M.; Gasbarri, C. Neutral liposomes containing crown ether-lipids as potential DNA vectors. Biochim. Biophys. Acta 2013, 1828, 2506-2512. [CrossRef]

32. Gasbarri, C.; Croce, F.; Meschini, I.; Bowen, C.H.; Marinelli, L.; di Stefano, A.; Angelini, G. Single-Walled Carbon Nanotubes in Highly Viscous Media: A Comparison between the Dispersive Agents [BMIM][BF4], L121, and Triton X-100. Chem. Eur. J. 2016, 22, 546-549. [CrossRef]

33. Angelini, G.; Gasbarri, C.; Kazarian, S.G. Pluronic L121, BMIM BF 4 and PEG-400 comparison to identify the best solvent for $\mathrm{CO}_{2}$ sorption. J. Mol. Liq. 2018, 258, 85-88. [CrossRef]

34. Angelini, G.; Gasbarri, C. Polymeric Aggregates in Ionic Liquids: The Green Future of the Delivery Systems. Curr. Drug Targets 2015, 16, 1606-1611. [CrossRef] [PubMed]

35. Fontana, A.; Viale, M.; Guernelli, S.; Gasbarri, C.; Rizzato, E.; Maccagno, M.; Petrillo, G.; Aiello, C.; Ferrini, S.; Spinelli, D. Strategies for improving the water solubility of new antitumour nitronaphthylbutadiene derivatives. Org. Biomol. Chem. 2010, 8, 5674-5681. [CrossRef] [PubMed]

36. Scotti, L.; Angelini, G.; Gasbarri, C.; Bucciarelli, T. Uncoated negatively charged silver nanoparticles: Speeding up the electrochemical synthesis. Mater. Res. Express 2017, 4, 105001. [CrossRef]

37. Muralia, G.; Vattikuti, S.V.P.; Kshetri, Y.K.; Lee, H.; Modigunta, J.K.R.; Reddy, C.S.; Park, S.; Lee, S.; Poornaprakash, B.; Lee, H.; et al. Near-infrared-activated Z-scheme NaYF4:Yb/Tm@Ag3PO4/Ag@g-C3N4 photocatalyst for enhanced H2 evolution under simulated solar light irradiation. Chem. Eng. J. 2021, 421, 129687. [CrossRef]

38. Nagajyothi, P.C.; Reddy, L.V.; Devarayapalli, K.C.; Vattikuti, S.V.P.; Wee, Y.J.; Shim, J. Environmentally Friendly Synthesis: Photocatalytic Dye Degradation and Bacteria Inactivation Using Ag/f-MWCNTs Composite. J. Clust. Sci. 2021, 32, 711-718. [CrossRef] 
39. Barbieri, F.; Würth, R.; Pattarozzi, A.; Verduci, I.; Mazzola, C.; Cattaneo, M.G.; Tonelli, M.; Solari, A.; Bajetto, A.; Daga, A.; et al. Inhibition of Chloride Intracellular Channel 1 (CLIC1) as Biguanide Class-Effect to Impair Human Glioblastoma Stem Cell Viability. Front. Pharmacol. 2018. [CrossRef]

40. Saeb, A.T.; Alshammari, A.S.; Al-Brahim, H.; Al-Rubeaan, K.A. Production of silver nanoparticles with strong and stable antimicrobial activity against highly pathogenic and multidrug resistant bacteria. Sci. World J. 2014, 2014, 704708. [CrossRef]

41. Shabatina, T.I.; Mascetti, J.; Ogden, J.S.; Sergeev, G.B. Competitive cryochemical reactions of transitino metal atoms, clusters and nanosized particles. Russ. Chem. Rev. 2007, 76, 1123-1137. [CrossRef]

42. Echlin, P. Handbook of Sample Preparation for Scanning Electron Microscopy and X-ray Microanalysis; Springer Science Business Media: Berlin/Heidelberg, Germany, 2009.

43. Gasbarri, C.; Ruggieri, F.; Foschi, M.; Aceto, A.; Scotti, L.; Angelini, G. Simple Determination of Silver Nanoparticles Concentration as $\mathrm{Ag}^{+}$by Using ISE as Potential Alternative to ICP Optical Emission Spectrometry. ChemistrySelect 2019, 4, 9501-9504. [CrossRef]

44. Luo, K.; Clair, T.P.s.; Goodman, D.W. Silver growth on TiO2(110) (1x1) and (1x2). J. Phys. Chem. B 2000, 104, 3050-3057. [CrossRef]

45. Wang, P.W.; Jiang, Y.; Hsu, J.C.; Chen, Y.Y.; Lin, Y.H.; Chen, H.L. Thermal Effect on Structure of Silver in Ion-Exchanged Soda-Lime Glasses and Aluminum-Doped Zinc Oxide Films. Adv. Mat. Sci. Eng. 2011, 2011, 7. [CrossRef]

46. Hammond, J.S.; Gaarenstroom, S.W.; Winograd, N. X-ray photoelectron spectroscopic studies of cadmium- and silver-oxygen surfaces. Anal. Chem. 1975, 47, 2193-2199. [CrossRef]

47. Zheng, J.; Ding, Y.; Tian, B.; Wang, Z.L.; Zhuang, X. Luminescent and Raman Active Silver Nanoparticles with Polycrystalline Structure. J. Am. Chem. Soc. 2008, 130, 10472-10473. [CrossRef]

48. Singh, A.K.; Khan, F.S.T.; Rath, S.P. Silver(III) Silver(III) Interactions that Stabilize the syn Form in a Porphyrin Dimer Upon Oxidation. Angew. Chem. Int. Ed. 2017, 56, 8849-8854. [CrossRef] [PubMed]

49. Hui, Y.; Yan-yu, R.; Tao, W.; Chuang, W. Preparation and antibacterial activities of Ag/Ag+/Ag3+ nanoparticle composites made by pomegranate (Punica granatum) rind extract. Results Phys. 2016, 6, 299-304.

50. Yang, X.; Du, Y.; Li, D.; Lv, Z.; Wang, E. One-step synthesized silver micro-dendrites used as novel separation mediums and their applications in multi-DNA analysis. Chem. Commun. 2011, 47, 10581-10583. [CrossRef]

51. Lanje, A.S.; Sharma, S.J.; Pode, R.B. Synthesis of silver nanoparticles: A safer alternative to conventional antimicrobial and antibacterial agents. J. Chem. Pharm. Res. 2010, 2, 478-483.

52. Standke, B.; Jansen, M. Darstellung und Kristallstruktur von $\mathrm{Ag}_{3} \mathrm{O}_{4}$. J. Solid State 1987, 67, 278-284. [CrossRef] 